\title{
USO DE TÉCNICA DE MEIO ALTERNATIVO DE RESOLUÇÃO DE CONFLITOS E A AUTONOMIA DAS MULHERES VÍTIMAS DE VIOLÊNCIA DOMÉSTICA À LUZ DA BIOÉTICA
}

http://dx.doi.org/10.21527/2176-6622.2018.50.139-151

Recebido em: 6/10/2017

Aceito em: 22/10/2017

\section{Gabriella Sousa da Silva Barbosa}

Mestranda em Direito e Instituições do Sistema de Justiça da Universidade Federal do Maranhão - Ufma. Advogada. Pesquisadora Capes. gssbarbosa@gmail.com

\section{Artenira da Silva e Silva}

Pós-doutora em Psicologia e Educação pela Universidade do Porto. Doutora em Saúde Coletiva pela Universidade Federal da Bahia. Mestre em Saúde e Ambiente pela Universidade Federal do Maranhão. Graduada em Psicologia pela Pontifícia Universidade Católica de São Paulo. Docente e pesquisadora do Departamento de Saúde Pública e do Mestrado em Direito e Instituições do Sistema de Justiça da Universidade Federal do Maranhão. Coordenadora de linha de pesquisa do Observatório Ibero-Americano de Saúde e Cidadania e coordenadora do Observatorium de Segurança Pública (PPGDIRUFMA/CECGP). Psicóloga clínica e forense. artenirassilva@hotmail.com

\section{Delmo Mattos}

Doutor em Filosofia pela UFRJ. Professor-colaborador no Programa de Pós-Graduação em Direito e Instituições do Sistema de Justiça pela Ufma. Professor permanente do Programa de Pós-Graduação (Mestrado) em Meio Ambiente da Universidade Ceuma. Líder do grupo de pesquisa Justiça, poder e relações éticas na contemporaneidade (CNPq) Pesquisador Fapema/CNPq. delmomattos@hotmail.com

\section{RESUMO}

A promulgação da Lei no 11.340/2006, Maria da Penha, marca a retirada das demandas referentes à violência doméstica do paradigma conciliatório dos Juizados Especiais em que os delitos por ela albergados até então eram julgados. Por outro lado, a Resolução do Conselho Nacional de Justiça no 125/2010, assim como o Novo Código de Processo Civil, privilegiam a utilização dos chamados meios alternativos para resolução de conflitos, iniciando uma nova perspectiva, a do privilégio à autocomposição. Nesse sentido, por meio de uma revisão bibliográfica e de três estudos de caso, concluiu-se que, mesmo diante da autonomia maculada de mulheres vítimas de violência doméstica e familiar, é possível a utilização da técnica da constelação familiar e/ou da mediação para a resolução de conflitos relativos à violência doméstica.

Palavras-chave: Violência doméstica. Técnica da constelação familiar. Mediação. Meios alternativos para resolução de conflitos. Autonomia.

\section{USE OF ALTERNATIVE PATTERNS OF CONFLICT RESOLUTION AND THE AUTONOMY OF WOMEN VICTIMS OF DOMESTIC VIOLENCE CONSIDERING BIOETHICS PRINCIPLES}

\section{ABSTRACT}

The promulgation of the no 11.340 / 2006 Law, that is, the Maria da Penha Law, marks the withdrawal of the demands related to domestic violence from the conciliatory paradigm of special courts in which these crimes were judged at first. On the other hand, the Resolution $\mathrm{n}$. $125 / 2010$ of the National Council of Justice, as well as the New Brazilian Code of Civil Procedure, favor the use of the so called alternative means for resolving conflicts, enhancing the practice of self-composition in several kinds of demands. Therefore through a bibliographical review and three cases studied, it was concluded that, even with the maculated autonomy of women victims of domestic and family violence, it is possible the use of the family constellation technique and / or of mediation in order to solve domestic violence conflicts.

Keywords: Domestic violence. Family constellation technique. Mediation. Alternative Means for resolving conflicts. Autonomy.

\section{SUMÁRIO}

1 Introdução. 2 Propostas da Atividade Judicante Perante os Desafios das Demandas de Violência Doméstica no Brasil. 3 Da Aplicação da Mediação em Demandas de Violência Doméstica Diante da Autonomia Comprometida da Mulher Violentada. 4 Da Possibilidade de Uso da Técnica da Constelação Familiar nos Casos de Violência Doméstica. 5 Considerações Finais. 6 Referências. 


\section{Direito:

\section{INTRODUÇÃO}

A técnica das Constelações Familiares foi criada no fim do século 20, objetivando, de modo fenomenológico e sistêmico, a representação de conflitos familiares e consequente percepção pelos pacientes, denominados constelados, das dificuldades emocionais e origem dos conflitos existentes em seus casos concretos (CÉSPEDES, 2017, p. 12).

Esta técnica, criada pelo alemão Bert Hellinger, passou a ser utilizada em diversas áreas, servindo, de um modo geral, para ampliar o diálogo entre os sujeitos que possuem restrições de caráter relacional em virtude de relações familiares mal-elaboradas emocionalmente, restringindo as suas formas de interagir nos seus ambientes de trabalho. No Direito tem-se por foco, quando se faz uso das constelações, o aprimoramento do diálogo entre as partes litigantes, com enfoque especial nas demandas de Direito de Família, visando a restabelecer um contato mais saudável entre os litigantes (CONSELHO..., 2014, p. 1).

Desse modo, a técnica das Constelações Familiares vem sendo utilizada, a partir dos anos 2000 no Direito brasileiro, como uma fase preparatória à utilização dos meios consensuais de resolução de conflitos, trabalhando as partes para que, por meio da percepção dos problemas-raiz daquela demanda trazida a juízo, estejam mais propícias a uma concreta resolução de seu problema judicializado (CÉSPEDES, 2017, p. 37).

Considera-se, em princípio, que nem todas as demandas são passíveis de serem mais bem resolvidas ou de terem seu potencial de conflito minimizado mediante a utilização de meios consensuais para resolução de seus conflitos. A fim de reafirmar este entendimento inicial, observa-se que uma das maiores problematizações quando da não existência da Lei Maria da Penha era a condução dos crimes com pena de até dois anos aos Juizados Especiais - caracterizados pela manutenção de um espírito conciliatório em prol da continuidade da família e a presença das transações penais, o que representava, no plano prático, a impunidade do agressor (BARSTED, 2011, p. 27).

É nesse sentido e tomando-se a utilização da técnica das Constelações Familiares como proposta precedente ao uso dos meios consensuais de resolução de conflitos (conciliação e mediação), que se analisa se o uso desta técnica pode ou não facilitar a percepção e compreensão de vítimas e agressores dos diversos fatores psicossocioculturais introjetados que se fazem presentes nas demandas referentes à violência doméstica e familiar contra mulheres.

Seguindo esse raciocínio, pretende-se analisar também a pertinência do uso da mediação nos conflitos supramencionados. Esta se caracteriza como um método supostamente pacífico de resolução ou administração de conflitos, conjuntamente à negociação e à conciliação, integrando, portanto, o grupo dos ditos meios mais adequados ou alternativos de resolução de conflitos autocompositivos, nos quais as partes tentam encontrar entre si a solução de suas demandas. Diferencia-se, desse modo, da arbitragem, também um meio alternativo, mas embasado pela heterocomposição, na qual um terceiro nomeado de árbitro torna-se responsável pela decisão que obrigará as partes (GRINOVER, 2009, p. 2).

A mediação, por meio da proposta de uma resolução de demandas por um viés não adversarial, acaba por apresentar uma lógica diferenciada daquela encontrada no uso comum do poder Judiciário. Diferentemente da racionalização ganhador-perdedor presente nas Varas de Justiça, na qual se estimula o antagonismo e a rivalidade entre as partes, a técnica tem o escopo de fazer autor e réu voltarem a dialogar (MUSZKAT, 2003, p. 34). Ou seja, em contextos de violência doméstica a mediação poderia favorecer uma percepção mais ampla do conflito vivenciado, favorecendo inclusive a responsabilização do réu e concedendo maior efetividade de sentenças porventura proferidas. Para além do consenso, a utilização da técnica de mediação, entre outros objetivos, visa a fazer as partes perceberem outras facetas do conflito-raiz sobre as quais possam não estar conscientes.

Busca-se, tanto na mediação quanto na aplicação da técnica constelar, que os envolvidos compreendam as circunstâncias que motivaram aquela ação judicial, ampliando-se a percepção de complexidade dos conflitos em questão e do seu poder de consequência sobre todos que estão relacionados a eles, direta ou indiretamente (FONSECA; SAUÁIA, 2014, p. 173). É nesse sentido que a utilização da técnica de mediação em conflitos familiares ganha destaque, uma vez que, saindo da lógica ganhador-perdedor, impraticável nas demandas 
envolvendo vínculos de paternalidade e conjugalidade, permite que as partes trabalhem os conflitos-raiz, de modo a diminuir futuros acessos ao Judiciário que reflitam resíduos daquelas demandas anteriores mal-resolvidas.

Conforme argumenta Bavaresco (2006), essas vias de acesso permitem aumentar a compreensão e o reconhecimento dos participantes, construir a possibilidade de ações coordenadas, mesmo que na diferença, incrementar os diálogos e a capacidade das pessoas e comunidades para se comprometerem responsavelmente com decisões e acordos participativos. Evidenciar a autonomia, democracia e cidadania é, em certo sentido, ocupar-se da capacidade das pessoas de se autodeterminarem em relação e com os outros, considerando-se as especificidades e vulnerabilidades das vítimas de violência doméstica.

Por conseguinte, a efetivação da ordem jurídica justa demanda a garantia de que o Judiciário esteja disposto a efetivar direitos, o que implica compartilhar direitos e deveres de maneira recíproca. Nesse sentido, deve-se conceber de forma recíproca e complementar dignidade e liberdade como elementos essenciais da ordem jurídica justa. Por sua vez, a reciprocidade é a condição da dignidade humana como pressuposto da autonomia da vontade.

Com o propósito de aprofundar os conceitos explorados ao longo do presente trabalho, como procedimento metodológico analisaram-se os resultados de três estudos de caso. O primeiro referente à introdução da técnica das Constelações Familiares no Brasil pelo magistrado Sami Storch, na Comarca de Castro Alves, no interior da Bahia; o segundo a análise da efetividade das audiências de fortalecimento - criadas e adotadas na 14a Vara Criminal de Belo Horizonte - e o terceiro abordando os impactos da instituição de um Núcleo Experimental de Mediação na Delegacia Especial de Atendimento à Mulher (Deam) no Estado de Sergipe.

\section{PROPOSTAS DA ATIVIDADE JUDICANTE PERANTE OS DESAFIOS DAS DEMANDAS DE VIOLÊNCIA DOMÉSTICA NO BRASIL}

Sabidamente, as demandas de violência doméstica não diminuíram com a criação da Lei Maria da Penha, de no 11.340/2006. Conforme os dados do Mapa da Violência de 2015 - Homicídios de Mulheres no Brasil (WAISELFISZ, 2015, p. 12), as taxas de mulheres assassinadas no país, que haviam regredido até 2003 (4,4\% a cada 100 mil habitantes), voltaram a subir após a promulgação da Lei Maria da Penha em 2006, chegando a 4,8\% a cada 100 mil habitantes em 2013. De modo a corroborar tal crescimento, em 2015, por exemplo, 63\% da população brasileira acreditava ter aumentado a violência contra a mulher (DATASENADO, 2013, p. 4).

Os dados e a própria percepção da violência doméstica e/ou intrafamiliar de gênero pela sociedade apontam para alguns dos desafios a serem transpostos por magistrados ao lidar com conflitos violentos embasados no gênero e nas relações de afeto e/ou coabitação atual ou pretérita. De um lado percebe-se que a mera aplicação da letra da lei, sem que se considere as bases transdisciplinares do referido dispositivo legal, define que se siga ignorando as especificidades e as complexidades das relações entre agredida e agressor - desde questões psicológicas, a exemplo da Síndrome da Mulher Agredida (SAUÁlA; ALVES, 2016, p. 92-93) - até a existência de vínculos permanentes entre as partes quando há filhos, frutos do relacionamento. De outro, está a ausência de legitimidade do poder Judiciário em legislar, devendo primar, aliado ao Ministério Público, pela busca de maior eficácia do texto legal.

É nesse sentido que se abordarão dois estudos de caso de procedimentos adotados por magistrados brasileiros ao atuarem diante de demandas de violência doméstica e familiar: a técnica das Constelações Familiares e a introdução das Audiências de Fortalecimento. A representatividade dos casos analisados expressa-se tanto pela atuação dos profissionais considerando integralmente as especificidades dos conflitos trabaIhados como pelos resultados alcançados com as propostas.

A utilização da terapia das Constelações Familiares como método auxiliar à prática forense no Brasil foi iniciada em 2006, com a atuação do magistrado Sami Storch, titular da Comarca de Castro Alves, interior da Bahia. Ressignificando a expressão Direito Sistêmico, o juiz propõe a utilização de um método sistêmico-fenomenológico de solução de conflitos, a atuar na origem do problema (CÉSPEDES, 2017, p. 37). 
Durante a introdução da terapia na Vara de Família do município, faziam-se três reuniões - terapia em grupo - com três casos constelados por dia. Segundo dados de 2012 e 2013, os resultados obtidos nas audiências, em sua maioria de casos de guarda, alimentos ou divórcio, mostraram-se positivos: $91 \%$ de conciliações em audiências nas quais uma das partes havia participado das Constelações e 100\% de acordos naquelas em que ambas as partes foram submetidas à terapia proposta (CONSELHO..., 2014, p. 1).

Storch na sua trajetória como jurista, primeiro na advocacia e depois na magistratura, percebeu que os relacionamentos humanos nem sempre se orientam pelas leis positivadas, que muitos dos conflitos vivenciados entre grupos ou entre indivíduos têm origem em questões mais profundas do que os fatos trazidos aos autos de um processo judicial; percebeu ainda que na presença de uma complexidade maior do que o que pode ser aparentemente percebido, os ditames das leis ou da decisão judicial não sanam a questão trazida ao Direito. Em sua experiência na magistratura observou que mesmo quando uma ou ambas as partes se sentiam aliviadas com o proferir da sentença, a questão permanecia, vindo posteriormente exigir sua resolução, retirando a tranquilidade e, muitas vezes, trazendo novamente à esfera jurídica os envolvidos (CÉSPEDES, 2017, p. 37).

A referida terapia foi incorporada pelo magistrado a partir da técnica da Constelação Familiar desenvolvida pelo filósofo, psicoterapeuta e teólogo alemão Bert Hellinger na década de 80 do século 20. Destaque-se que o estudioso não criou efetivamente a técnica, mas sim transformou e uniu outras anteriormente existentes em saberes de comunidades tribais, teorias e métodos de outros autores da Filosofia, Teologia, Psicologia e Psicanálise, extraindo princípios que norteariam a nova propositura de abordagem, revestindo-a de um caráter mais científico (CÉSPEDES, 2017, p. 12).

Através do estudo da dinâmica de grupo, do psicodrama do psiquiatra Jacob Moreno, da Terapia Contextual de Ivan Boszormenyi-Nagy, da Técnica da Família Simulada de Virginia Satir, da terapia primal, da análise transacional e de diversos métodos hipnoterapêuticos, desenvolveu a Constelação Familiar Sistêmica (ALMEIDA, 2008 p. 1).

A técnica das Constelações Familiares de Hellinger pode ser considerada uma abordagem da Terapia Sistêmica Fenomenológica (CARVALHO, 2012, p. 43). Esta última foi criada por Edmund Husserl, mais bem descrita em sua obra Investigações Lógicas, de 1901, quando substituiu a expressão "psicologia descritiva" que utilizava até então (ZILES, 2007, p. 4). A teoria de Husserl atingiu seu momento marcante na década de 20, quando surgiram escolas que acabaram por utilizar alguns aspectos de suas concepções para as construções teóricas que intentavam, como a ontologia existencial de Heidegger e a ética dos valores de Max Scheler (ZILES, 2007, p. 1).

A fenomenologia husserlniana possui o objetivo inicial de "[...] satisfazer à objetividade do conhecimento, seja ele ideal ou real, e à subjetividade do cognoscente" (ZILES, 2007, p. 3) e, para tanto, tem por meta a construção de uma ciência da essência do conhecimento ou doutrina universal das essências (SILVA; LOPES; DINIZ, 2006, p. 255).

O termo fenomenologia significa estudo dos fenômenos, daquilo que aparece à consciência, daquilo que é dado, buscando explorá-lo. A própria coisa que se percebe, em que se pensa, de que se fala, tanto sobre o laço que une o fenômeno com o ser de que é fenômeno, como sobre o laço que o une com o Eu para quem é fenômeno (SILVA; LOPES; DINIZ, 2006, p. 255).

É nesse sentido que as observações de Bert Hellinger levaram-no a conceber uma técnica cujo trabalho consiste na transformação dos vínculos não perceptíveis conscientemente dentro de uma família ou um sistema de vínculos invisibilizados, por meio de uma representação espacial (ALMEIDA, 2008, p. 1). Ademais, concebe-se a existência de um "movimento da alma" que interligaria os participantes da terapia por meio da representação, uma vez que haveria um equilíbrio do grupo, portanto sistêmico (CHIQUETTI; CRUZ, 2016, p. 11).

Nas constelações familiares, praticadas em grupo ou na terapia individual, diversos elementos da psicoterapia se desenvolvem e convergem num instrumental representativo, capaz de trazer à luz os processos anímicos, vivenciá-los e reduzi-los ao núcleo essencial que permite soluções. Ao mesmo tempo, esse instrumental leva a profundas experiências e descobertas humanas, que apontam para amplos domínios coletivos e espirituais, ultrapassando as fronteiras, por vezes estreitas, da psicoterapia. A solução de problemas psíquicos associa-se à descoberta das ligações da alma, em conexão com as ocorrências e os destinos familiares e com os grupos e os contextos maiores que os abrangem (SCHNEIDER, 2007, p. 9). 
A fim de alcançar os objetivos propostos, a técnica é regida por três princípios básicos, denominados ordens do amor e que representam as necessidades essenciais para a manutenção sadia dos relacionamentos humanos e da constituição dos sistemas, ou seja, de grupos sociais. São elas: o pertencimento ou vinculação a um grupo; a necessidade de se estabelecer uma ordem, a importância de se estruturar o sistema em relação ao tempo de ingresso nele, à função ou à hierarquia entre os membros e a manutenção entre o dar e o receber (HELLINGER, 2015, p. 25).

Para o autor, tais ordens do amor não são criadas, mas descobertas, existindo mesmo diante da incompreensão dos membros, daí advindo, portanto, a possibilidade de, por meio da representação, fazê-las visíveis aos indivíduos que buscam a terapia. O princípio do pertencimento pondera que nenhum membro do grupo pode ser excluído dele por nenhum motivo. Quanto à hierarquia, têm-se não só que se deve respeitar a origem cronológica, quando pais devem preceder aos filhos, por exemplo, como também a hierarquia pelo progresso, na qual o novo sistema deve prevalecer em relação ao anterior. Por fim, o dar e receber/tomar salienta a necessidade de um equilíbrio entre os membros de um sistema, não só pela doação - um filho, eterno devedor dos pais, mas os filhos também dão continuidade à família ou thes doam uma realização para a humanidade, por exemplo - como pela compensação de ações nos relacionamentos conjugais (CHIQUETTI; CRUZ, 2016, p. 13).

As culpas e as consequências retornam às pessoas a que pertencem, e começa a reinar a compensação por meio do bem, substituindo a necessidade sinistra de equilibrar por meio do funesto, que gera o mal a partir do mal. O sucesso acontece quando os mais novos aceitam o que receberam dos mais velhos. Os excluídos recuperam seu direito de ser acolhidos e nos abençoam ao invés de nos amedrontarem. Quando lhes damos um lugar em nossa alma, ficamos em paz com eles. A partir do momento que estamos de posse de todos os que nos pertencem, de todos os que fazem parte do nosso sistema familiar, sentimo-nos inteiros e plenos no amor que pode fluir e crescer. Aquilo que se coloca a caminho, sem nenhuma intenção, sem medo e sem vontade de ajudar alguém de qualquer maneira. Por meio do trabalho com os representantes eles se movimentam e encontram soluções que estão além da influência do constelador ou do terapeuta (CARVALHO, 2012, p. 43).

É regida pelos referidos princípios que a terapia se desenvolve tanto de modo individual, com a presença do constelado - paciente - e do constelador - terapeuta - por meio da utilização de bonecos ou qualquer objeto que sirva para representar os membros do sistema, ou mesmo em grupo, quando um terceiro é chamado a atuar como um membro do sistema do paciente, percebendo-se as sensações e movimentos que, até então, estavam ocultos naquele sistema representado (CÉSPEDES, 2017, p. 19).

O que há de extraordinário nas constelações familiares é primeiramente o próprio método. É singular e fascinante observar, quando um cliente coloca em cena pessoas estranhas para representar seus familiares em suas relações recíprocas, como essas pessoas, sem prévias informações, vivenciam sentimentos e usam palavras semelhantes às deles e, eventualmente, até mesmo reproduzem os seus sintomas. Quando os representantes são instados a expressar em movimentos o que sentem, eles frequentemente exprimem uma dinâmica da alma que revela destinos ocultos, que o próprio cliente desconhecia. Algumas vezes, o que os representantes sentiram só fica claro para o cliente depois que ele se informa com sua família (SCHNEIDER, 2007, p. 10).

Diante da proposta trazida pelo magistrado ao Direito pátrio o poder Judiciário tem absorvido a técnica para maximizar a possibilidade de se obter a resolução mais adequada a conflitos que demonstrem intensa complexidade. Segundo dados do Conselho Nacional de Justiça - CNJ (CONSELHO..., 2016, p. 1) ao menos 11 Estados já utilizam esta técnica, a exemplo de São Paulo, Rondônia, Pará e Alagoas. No Distrito Federal a prática autorizada pelo juiz titular de Direito da Vara da Infância e Juventude - VIJ - Renato Scussel, em uma unidade de acolhimento, Lar São José, no ano de 2015, sob influência da pesquisa acadêmica da voluntária Adhara Campos, suscitou a criação do Projeto Constelar e Conciliar (CONSELHO..., 2016, p. 1).

Também com resultados positivos e demonstrando uma atuação propositiva dos operadores do Direito diante dos desafios das complexas relações travadas em meio à violência doméstica está a instituição das Audiências de Fortalecimento. Idealizadas pelo magistrado Marcelo Gonçalves de Paula, titular da 14a Vara Criminal de Belo Horizonte-MG - especializada em crimes albergados pela Lei Maria da Penha - tais audiências são realizadas em julgamentos de Medidas Protetivas de Urgência, quando o agressor é reincidente no descumprimento das mesmas (UFMG, 2017, p. 1). 
"A prática permite a inversão dos papéis", diz o juiz idealizador do projeto, Marcelo Gonçalves de Paula. Segundo ele, no momento dessa audiência, há uma troca de posição. "O ofensor experimenta pela primeira vez a escuta obrigatória e essa mulher, que até então oprimida, ganha voz e sai da posição de constrangimento e medo", explica o magistrado, que aplicou a Audiência de Fortalecimento em 17 casos (CONSELHO..., 2017, p. 1).

Iniciada em abril de 2017, a adoção desse tipo de audiência apresentou em sua totalidade de casos a interrupção da reincidência em descumprir as ordens judicias. É possível que este resultado seja oriundo, senão completamente, ao menos parcialmente, da ressignificação daquele processo judicial e dos múltiplos fatores etiológicos nele implicados, posto que agora ao agressor - obrigado a comparecer a uma audiência para ouvir a agredida - é possibilitado ultrapassar a naturalização do ciclo de violência e conseguir compreender os anseios e consequências de seus atos diante daquela mulher com quem mantém ou já manteve algum vínculo afetivo. Assim sendo, em audiência, o agressor precisará ouvir sua vítima, que, cumpre lembrar, não é uma estranha, mas alguém de sua convivência afetiva presente ou pretérita, ou seja, ouvirá alguém que não lhe é indiferente, pois se assim o fosse a violência levada a Juízo sequer teria existido.

É em razão dos resultados obtidos nas Varas de Família com a utilização das técnicas em questão e do histórico negativo da prática de conciliações diante dos contextos de violência doméstica e/ou intrafamiliar contra a mulher, antes da vigência da Lei Maria da Penha, no 11.340/2006, que se pretende analisar no presente estudo a pertinência ou não da aplicação da técnica das Constelações Familiares e da mediação também às demandas de violência doméstica.

\section{DA APLICAÇÃO DA MEDIAÇÃO EM DEMANDAS DE VIOLÊNCIA DOMÉSTICA DIANTE DA AUTONOMIA COMPROMETIDA DA MULHER VIOLENTADA}

Retomando as lições da saudosa professora Ada Pellegrini Grinover (2009, p. 3-4), diferentemente da diversidade de instrumentos utilizados como equivalentes jurisdicionais no chamado sistema multiportas, como o utilizado nos Estados Unidos, no Brasil o uso dos métodos consensuais de conflitos pode ser dividido entre a negociação, a conciliação e a mediação. A primeira é encontrada quando as partes chegam a um consenso sem a necessidade de intervenção de um terceiro, sendo utilizada quando as partes mantêm um bom relacionamento e conseguem solucionar autonomamente a controvérsia de modo objetivo.

Quanto à conciliação e à mediação, ambas necessitam de um terceiro facilitador, cuja atividade diferenciar-se-á em conformidade com o método escolhido. Na conciliação, a atividade do referido conciliador dar-se-á pelo incentivo, facilitação ou auxílio para que as partes, que não possuem um relacionamento para além de uma questão superficial, possam se autocompor. Diferentemente, na mediação, a função do terceiro será mais provocativa, de modo a trazer à tona aspectos do conflito não percebidos pelas partes, objetivando-se, portanto, não um acordo, mas o restabelecimento da possibilidade de um diálogo saudável entre as partes (GRINOVER, 2009, p. 3-4).

Na mediação, o mediador não interfere na decisão nem induz o acordo, apenas facilita a comunicação entre as partes, permitindo que decidam livremente. Ele deve analisar, em profundidade, o contexto do conflito, permitindo sua ressignificação e, conseqüentemente, novas formas de convivência e prevenção de novos conflitos. Outra diferença fundamental entre a mediação e outro instrumento consiste na presença de um terceiro imparcial, que não opera, em princípio, com base em julgamentos de valor, mas permite, pelo manejo da sua intervenção, que as partes oponentes reflitam e cheguem a encontrar um caminho para a superação do conflito, identificando suas raízes e reorientando atitudes e ações na busca de uma superação. Com isso, pretende-se transcender o "modelo punitivo" para um "modelo de justiça penal diferenciado", pautado no restabelecimento do diálogo, na construção de pactos e acordos diante de interesses divergentes e na ressignificação de contendas, proporcionando a retomada da autodeterminação das pessoas (NOBRE; BARREIRA, 2008, p. 146).

No que respeita à aplicação dos referidos meios aos casos de violência doméstica e familiar no país, é fundamental trazer algumas breves pontuações históricas ao debate. A criação da Lei no 11.340/2006, denominada Lei Maria da Penha, é reconhecida como um marco para a proteção de mulheres em casos de violência doméstica no país. Instituída por influência de uma condenação no caso Maria da Penha Maia Fernandes, da Corte Interamericana de Direitos Humanos ao Estado Brasileiro, no ano de 2001, por omissão e negligência no enfrentamento das questões relativas à violência doméstica (DIAS, 2007, p. 14), em específico por descum- 
primento ao artigo 70 da Convenção de Belém do Pará, assim como aos artigos 1ํ, 8ㅇ e 25 da Convenção Americana de Direitos Humanos, tem-se que a lei reflete um longo processo de luta dos movimentos feministas e de organizações de mulheres da sociedade civil ao longo de décadas no país (CALAZANS; CORTES, 2011, p. 56).

A luta pelo direito a uma vida sem violência, que possibilitou a aprovação da Lei Maria da Penha, em 2006, é um caso exemplar de exercício de uma cidadania ativa expressa no discurso e na atuação das feministas no espaço público. Sintetiza, também, a longa interlocução das feministas com os poderes Legislativo e Executivo e aponta para a necessidade de investimentos contínuos no diálogo com o poder judiciário e com as demais instituições da justiça (BARSTED, 2011, p. 15).

Pautando-se por uma base principiológica inspirada tanto no Direito Internacional quanto no respeito ao constitucionalismo pátrio, há que se conceber a Lei Maria da Penha, no 11.340/2006, como um avançado instrumento de proteção das mulheres em situação de violência doméstica e familiar (LAVIGNE; PERLINGEIRO, 2011, p. 290).

Enquanto um construído histórico, os direitos humanos das mulheres não traduzem uma história linear, não compõem uma marcha triunfal, nem tampouco uma causa perdida. Mas refletem, a todo tempo, a história de um combate, mediante processos que abrem e consolidam espaços de luta pela dignidade humana, como invocam, em sua complexidade e dinâmica, o movimento feminista, em sua trajetória plural (PIOVESAN; PIMENTEL, 2011, p. 101).

Refletindo o trabalho de décadas de lutas sociais, tanto no Direito Internacional quanto interno, a Lei Maria da Penha representa o principal diploma pátrio no combate à violência doméstica e familiar contra a mulher, tomando por base a principiologia advinda do Direito Internacional dos Direitos Humanos (LAVIGNE; PERLINGEIRO, 2011, p. 290), especialmente aqueles oriundos dos tratados internacionais de proteção das mulheres, dos quais o Brasil é signatário, como a Convenção para Prevenir, Punir e Erradicar a Violência contra as Mulheres - Convenção de Belém do Pará de 1994, e a Convenção para Eliminar Todas as Formas de Discriminação contra a Mulher, da ONU, 1979 (KATO, 2011, p. 350).

Antes da promulgação da Lei 11.340/2206, havia nomeadamente um conflito de interpretação entre a Convenção de Belém do Pará e a Lei no 9.099/95, Lei dos Juizados Especiais, no que tange à violência doméstica pautada no gênero. Enquanto a primeira considera a violência contra a mulher uma violação aos direitos humanos e, portanto, de gravíssima lesividade, os Juizados Especiais - e suas máximas pela prevalência da conciliação, informalidade e celeridade processual - eram os responsáveis pelo julgamento dos crimes considerados de menor potencial ofensivo, aqueles cujas penas não superem dois anos e, portanto, considerados como crimes de menor importância (BARSTED, 2011, p. 27).

É nesse sentido que os crimes de lesão corporal de natureza leve e de ameaça, por exemplo, respectivamente previstos entre os artigos 129 e 147 do Código Penal, eram considerados, nesse contexto anterior à Lei Maria da Penha, crimes de menor potencial ofensivo. Ignorou-se toda a complexidade advinda da violência moral, física ou psicológica pautada no gênero, reduzindo-a, minimizando-a e, portanto, concorrendo para sua invisibilidade, impunidade e seu consequente crescimento, em um ciclo retroalimentável.

No balanço dos efeitos da aplicação da Lei 9.099/1995 sobre as mulheres, diversos grupos feministas e instituições que atuavam no atendimento a vítimas de violência doméstica constataram uma impunidade que favorecia os agressores. Cerca de $70 \%$ dos casos que chegavam aos Juizados Especiais tinham como autoras mulheres vítimas de violência doméstica. Além disso, 90\% desses casos terminavam em arquivamento nas audiências de conciliação sem que as mulheres encontrassem uma resposta efetiva do poder público à violência sofrida. Nos poucos casos em que ocorria a punição do agressor, este era geralmente condenado a entregar uma cesta básica a alguma instituição filantrópica. Os Juizados Especiais, no que pese sua grande contribuição para a agilização de processos criminais, incluíam no mesmo bojo rixas entre motoristas ou vizinhos, discussões sobre cercas ou animais e lesões corporais em mulheres por parte de companheiros ou maridos. Com exceção do homicídio, do abuso sexual e das lesões mais graves, todas as demais formas de violência contra a mulher, obrigatoriamente, eram julgadas nos Juizados Especiais, onde, devido a seu peculiar ritmo de julgamento, não utilizavam o contraditório, a conversa com a vítima e não ouviam suas necessidades imediatas ou não (CALAZANS; CORTES, 2011, p. 42). 


\section{Direito自 Debate}

Percebe-se, então, que um dos marcos mais significativos da Lei Maria da Penha e fruto de ampla comemoração pelos movimentos civis que atuaram pela instituição desse diploma legal foi a retirada dos crimes de violência doméstica com pena de até 2 anos da alcunha de menor potencial ofensivo, estimulando-se a criação dos Juizados especializados em violência doméstica e familiar contra a mulher. Atribui-se uma atuação diferenciada da Justiça criminal em tais Juizados, uma vez que para além das responsabilidades criminais e distribuição das penas, deve-se adotar medidas para enfrentar a violência de gênero em seus efeitos diretos e indiretos contra a autonomia e o exercício de direitos das vítimas (PASINATO, 2011, p. 134).

Em sede de violência doméstica o juiz não pode propor composição de danos ou aplicação imediata de pena não privativa de liberdade (Lei 9.099/95, art. 72). Não há possibilidade de o Ministério Público sugerir transação ou a aplicação imediata de pena restritiva de direito ou multa (Lei 9.099/95, art. 76). Igualmente não é possível a suspensão condicional do processo (Lei 9.099, art. 89) (DIAS, 2007, p. 72).

É nesse mesmo sentido que o texto da Lei Maria da Penha é literal em seu artigo 41, afastando qualquer dúvida acerca da inaplicabilidade dos instrumentos da Lei no 9.099/95 aos casos de violência doméstica e familiar. Há que se questionar, porém, se, mesmo diante do afastamento da conciliação, característica dos Juizados Especiais, há a impossibilidade de uso dos demais meios consensuais de resolução de conflitos nas demandas referentes à violência doméstica. Tal problematização deve-se à intenção explícita de ressignificar a complexidade desses tipos de conflitos para vítimas e agressores, intentando, em última análise, dar maior efetividade às sentenças prolatadas, assim como prevenir a reincidência ou aceitação de futuras violências de gênero, cometidas ou sofridas pelas mesmas partes.

Nesse ponto é que se faz fulcral a consideração acerca da autonomia da mulher no processo de mediação, uma vez que a finalidade da atuação das Instituições do Sistema de Justiça nessas demandas deve prezar em primeiro lugar pela proteção da vítima - o que poderia ser colocado em risco caso a decisão autocompositiva estivesse eivada por uma autonomia viciada.

A autonomia da vontade pode ser entendida como uma propriedade natural do ser humano, advinda de sua personalidade jurídica. É considerada expressão da liberdade jurídica individual, dando a cada sujeito a possibilidade de agir em conformidade com as deliberações de sua racionalidade (ALVES, 2007, p. 22-23).

É indubitável, porém, que a autonomia de mulheres vítimas de violência doméstica e familiar está afetada, vez que suas decisões e escolhas inserem-se no contexto do ciclo de violência. Do mesmo modo, retirando-se os casos concretos de inserção em extrema patologia, a mulher ainda é sujeito livre e autônomo.

O que se argumenta, portanto, é que é impossível um agir com autonomia absoluta, posto que "tendo em vista o controle social, o estado psíquico do ser humano, as suas relações sociais, se torna impossível falar numa autonomia pura, desvinculada de qualquer coação interna ou externa [...]" (ALECRIM; SILVA; ARAÚJO, 2014, p. 160). Deve-se respeitar, então, suas escolhas, sem ignorar as complexidades do caso concreto, auxiliando a mulher, de modo a transformar sua vulnerabilidade em empoderamento.

Para muitas das teorias críticas, autonomia e conquista da liberdade são conceitos e princípios que se misturam na busca pela igualdade social, na crítica a todas as formas de opressão social ou mesmo na proteção de pessoas e/ou comunidades socialmente vulneráveis. No entanto, para além do princípio da autonomia, muitas vezes mecanicamente referenciado pela teoria principialista, as perspectivas críticas apontam para a necessidade de se demarcar a fronteira de situações em que a autonomia pode ser mascarada pela coerção da vontade, explicitando um dos aspectos fundamentais da perspectiva política do conceito de vulnerabilidade (DINIZ; GUILLHEM, 2000, p. 2).

Conforme destaca Bavaresco (2006), a autonomia no processo de mediação é uma forma de produzir diferenças e tomar decisões em relação às vicissitudes do conflito que se encontram impressas nos indivíduos e os configura em termos de identidade e cidadania. Trata-se, portanto, de um trabalho de reconstrução simbólica dos processos conflitivos das diferenças que permite formar identidades culturais, visando a integrar os conflitantes com um sentimento de pertinência comum. Pode-se considerar que a mediação aplicada aos casos de violência doméstica contribui para favorecer a responsabilização do agressor e para dar maior segurança à vítima. Assim sendo, seu uso nestes casos pode ser entendido como medida de prevenção, cuja aplicação é prevista no texto legal. 
Dentro dessa linha de pensamento, há que se reconhecer que o conjunto de direitos existenciais que compõem a dignidade pertence aos homens em igual proporção. Conforme essa determinação, fica evidente não ser possível considerar em maior ou menor dignidade, pelo menos no sentido aqui atribuído à expressão, de conjunto aberto de direitos existenciais. Com efeito, Zisman (2005, p. 23) conclui que a condição humana fornece ao ser a capacidade de envergar a autonomia, a liberdade e a responsabilidade, e são tais condições ínsitas de se ser homem ou mulher que ensejam o conteúdo ao princípio da dignidade da pessoa humana, princípio este que tem o escopo de catalisar primariamente a efetividade dos direitos fundamentais, permitindo, de tal forma, uma plausível aplicação dos mandamentos constitucionais pertinentes e possibilitando, portanto, que as mulheres não sejam destituídas de sua parcela de autonomia e liberdade de decisão, constituintes de sua dignidade humana, mesmo quando tal autonomia estiver maculada. Ou seja, não se pode desconsiderar o comprometimento de autonomia da mulher agredida, mas também não se pode ignorar completamente a autonomia a que faz jus esta mulher.

A partir de então, percebe-se que o uso da mediação pode ser útil diante de conflitos referentes à violência doméstica, de modo a se problematizar sua utilização em concomitância ou separadamente à técnica da Constelação Familiar Sistêmica.

\section{DA POSSIBILIDADE DE USO DA TÉCNICA DA CONSTELAÇÃO FAMILIAR NOS CASOS DE VIOLÊNCIA DOMÉSTICA}

Concebendo-se o uso da técnica da Constelação Familiar como um procedimento a auxiliar uma compreensão mais ampla dos problemas judicializados, em especial os que permeiam a complexidade das relações familiares, e, principalmente, considerando-se sua adoção precedendo a utilização de qualquer tentativa de resolução consensual de conflitos, como adiantado supra, é necessário, antes, que se discuta a possibilidade de uso de um meio consensual aos casos de violência doméstica, tendo-se o especial cuidado de não propor qualquer alternativa diante desses casos que contribuam para minimizá-los ou que possam concorrer para a impunidade dos agressores de violência doméstica e/ou intrafamiliar de mulheres.

Dispõe a Resolução no 125 de 2010 do Conselho Nacional de Justiça em seu artigo 1 que a Política Judiciária Nacional de tratamento aos conflitos de interesses tem por objetivo a solução dos conflitos pelos meios mais adequados à sua natureza e peculiaridade - permitindo-se que se conclua haver franca consideração às especificidades e complexidades das demandas referentes à violência doméstica.

É nítido e justificável o ranço e rechaço, especialmente dos movimentos feministas, às conciliações nas demandas de violência doméstica, uma vez que as diversas vulnerabilidades que a mulher vítima deste tipo de violência exibe, não possibilitam que ela atue em igualdade de condições com seu agressor em um contexto de conciliação. Não há que se negar, no entanto, a importância da mediação para o restabelecimento do diálogo nos conflitos em que o gênero foi a justificativa para a violência (NOBRE; BARREIRA, 2008, p. 149).

\footnotetext{
Quer-se com isso apresentar a viabilidade da mediação, levando em consideração suas limitações, como uma forma facilitadora, para que qualquer tipo de relação que subsista possa ser vivenciada sem violência. Isso porque, nos casais que viveram conflitos violentos, se as partes não forem bem trabalhadas individualmente e na mediação, a cada novo conflito, há uma grande possibilidade de novos episódios de violência. Assim, a partir desse novo plano familiar, construído por ambas as partes, haverá provavelmente prevenção da violência. Lembrando sempre que o acordo não parte de uma tentativa de manter a harmonia do casal, mas buscar o respeito entre as pessoas, independente das relações envolvidas (RAMOS, 2011, p. 108).
}

Observe-se, então, as ponderações de Maria Teresa Nobre e César Barreira (2008, p. 149-152) a respeito de um estudo de caso sobre o estabelecimento de um núcleo experimental de mediação na Delegacia Especial de Atendimento à Mulher (Deam) do Estado de Sergipe. O primeiro ponto a ser considerado é ser incontestável que a intervenção judicial não é suficiente para a inibição da violência doméstica de gênero, vez que o que embasa os atos deste tipo de violência são conceitos machistas e sexistas introjetados e naturalizados pelo agressor e vítima, que internalizam como normais e aceitáveis os atos de sujeição, humilhação, controle e posse das mulheres, os quais decisões e sentenças de caráter meramente punitivos não são capazes de conter ou coibir. 
Faz-se oportuno considerar que a proposta de utilização da mediação perante crimes de violência doméstica e de gênero, não visa a impedir ou dificultar a punição dos agressores, mas sim viabilizar maior efetividade às decisões e sentenças prolatadas, trazendo à baila facetas dos conflitos não percebidos por ambos e consequentemente viabilizando a consciência de responsabilização dos agressores e de empoderamento das vítimas.

No ano de 2001 o governo do Estado de Sergipe, por meio de concurso público realizado para ampliação das Delegacias de Polícia, acabou por assumir o compromisso de renovação e modificação das práticas policiais. Criou-se, assim, um processo de formação policial diante do projeto de construção de um Centro de Atendimento a Grupos Vulneráveis, integrado pelas Delegacias Especiais de Atendimento à Mulher, a Crianças e Adolescentes e de Atendimento a Grupos Vulneráveis - idosos, homoafetivos, profissionais do sexo, portadores de necessidades especiais e grupos vítimas de discriminações (NOBRE; BARREIRA, 2008, p. 148).

Os serviços prestados pela Delegacia da Mulher, atendendo às demandas das mulheres e desenvolvendo ativi-
dades que eram identificadas como "extrapoliciais" pela corporação da Polícia Civil, pela maioria dos policiais
lotados na Deam e pelo movimento feminista, apontavam a necessidade de mudanças das suas práticas ou
uma ressignificação do trabalho ali desenvolvido. Assim, a especificidade dos atendimentos às demandas das
mulheres e a predominância das ações policiais, ao longo de quase duas décadas, como práticas de renegocia-
ção de interesses, conciliação entre as partes e mediação de conflitos, levou o grupo de delegadas, que estava
participando do processo de construção do Centro de Atendimento a Grupos Vulneráveis, a propor a instala-
ção de um Núcleo de Mediação de Conflitos no novo complexo policial (NOBRE; BARREIRA, 2008, p. 148).

Com a criação do referido Núcleo de Mediação de Conflitos na Deam, houve uma transformação no formato desta Delegacia, assim como a sua vinculação a um complexo policial, o qual não apenas se encontrava no mesmo espaço físico da Delegacia, como viu-se submetido a uma coordenação unificada e com setores comuns. Tais mudanças garantiram, segundo depoimentos das delegadas e dos agentes penitenciários da Deam, melhores condições de trabalho, assim como um aumento da satisfação e valorização profissional (NOBRE; BARREIRA, 2008, p. 150).

Do mesmo modo, ficou evidente no estudo de caso em comento que a ressignificação do trabalho policial, por meio da instituição do Núcleo de Mediação na Delegacia Especial, trouxe maior visibilidade ao trabaIho dos agentes policiais e delegadas, facilitando o acesso da população à Deam. Não só o estigma da mulher vítima de violência que registrava a ocorrência e depois a retirava foi superado, por meio da maior importância dada à qualidade do serviço prestado, com a escuta e acolhida da mulher, observando-se, inclusive, uma redução da reincidência (NOBRE; BARREIRA, 2008, p. 150).

Em relação à mediação e à conciliação, Sales $(2003$, p. 33) identifica que o princípio da autonomia privada alcança evidente e inocultável importância, pois possibilita a própria existência destes meios de solução de conflitos. Nesse sentido, as partes decidem aceitar a mediação e a conciliação para pôr fim ao litígio existente ou para prevenir um litígio futuro e, após, decidem entabular ou não o acordo, sempre como fruto da válida manifestação da própria vontade. Com efeito, segundo observa Vezzulla (2008, p. 122):

[...] o princípio da autonomia privada, nestes termos considerado, permite que as partes possam resolver suas controvérsias por si mesmas, sem afronta ao princípio constitucional da inafastabilidade da jurisdição, previsto no inciso XXXV do artigo 5o da Constituição Federal, segundo o qual a lei não pode excluir da apreciação do poder Judiciário lesão ou ameaça a direito.

Existem diversos autores que se referem ao princípio da autodeterminação, em razão do qual o acordo entre as partes é sempre obtido de forma voluntária, sem imposições ou coerção, permitindo aos participantes abandonar o processo a qualquer momento. É nesse sentido que se fazem pertinentes as lições de Débora Diniz (2008, p. 212). Em casos de autonomia viciada, como os das mulheres agredidas, faz-se necessário questionar se a retirada por completo de suas capacidades decisórias não acaba por constituir um mecanismo de reforço à opressão.

Sendo assim, conforme expressa Sales (2003, p. 45), a não observância do princípio da autonomia privada nos processos de mediação e conciliação enseja duas consequências imediatas, uma vez que para além de seus limites há a ilicitude: a) não reconhecimento do acordo firmado por meio destes processos pela ordem jurídica; b) responsabilidade pelos danos daí decorrentes. 
Demonstrou-se o avanço da proposta no Estado de Sergipe - indo de encontro às críticas provenientes dos movimentos feministas em relação ao uso de meios alternativos em demandas de violência doméstica que, superando-se a antiga lógica conciliatória, proveniente dos Juizados Especiais, por meio das mediações trabalhadas na Deam buscava-se a compreensão do conflito e não a coação da mulher em perdoar o agressor, possibilitando à reclamante que se dirigisse diretamente ao Cartório para encaminhamento do caso à Justiça, assim como a propositura de reflexão e entendimento do agressor da gravidade de sua conduta, as causas do seu comportamento e a identificação das possibilidades de mudança (NOBRE; BARREIRA, 2008, p. 150-152).

Por último, a mediação de conflitos só se aplica aos casos que envolvem os chamados "direitos disponíveis". Esta, no entanto, está excluída nas seguintes situações: a) quando vislumbrada uma grande desproporção de poder entre as partes, sobretudo de ordem econômica, capaz de inviabilizar a consecução de acordos satisfatórios; b) quando há cronicidade da violência; c) quando o conflito possuir uma importância que supera os atos violentos, ou seja, se a convivência litigiosa é necessária para manter a própria relação afetiva do casal (NOBRE; BARREIRA, 2008, p. 150-151).

É nesse sentido que, mesmo diante da possibilidade de mediação aqui defendida, esta deve levar em conta as especificidades de cada caso concreto, assim como a vulnerabilidade da mulher agredida e sua vontade, prezando-se sempre não pelo retorno da conjugalidade, mas pela possibilidade de restabelecimento de diálogo entre as partes nos casos em que isso seja necessário - a exemplo das situações em que haja filhos entre agressor-agredida.

Desse modo estar-se-á respeitando os ditames da Secretaria Especial de Direitos Humanos (2008, p. 4), a qual prevê que a orientação de não mediação a conflitos cuja caracterização é de serem considerados como grave violação aos direitos humanos, tal qual a violência doméstica, uma vez que a proposta defendida é promover uma maior e melhor percepção do agressor e da vítima no que tange à complexidade da vulnerabilidade da vítima e de seus filhos nas demandas de violência doméstica judicializadas, favorecendo maior efetividade das decisões e sentenças prolatadas, além de poder haver maior garantia de prevenção de novos atos de violência.

Considera-se assim que tanto a utilização da mediação quanto da técnica de Constelação Familiar associada ou isoladamente pode configurar uma ferramenta eficiente para favorecer o manejo de demandas de violência doméstica, de modo a trabalhar os conflitos emergentes no seio da relação de convivência entre agressor-agredida, para além da superfície da tipificação dos crimes levados a juízo.

\section{CONSIDERAÇÕES FINAIS}

A técnica das Constelações Familiares é pautada em três princípios básicos, também denominados Ordens do Amor. Pertencimento, respeito à hierarquia e necessidade de dar e receber/tomar devem pautar a harmonia das relações familiares e precisam estar conscientes para os indivíduos membros de um determinado sistema familiar.

Nesse sentido, por meio da representação é permitido ao constelado, tanto individualmente e com a consequente utilização de bonecos ou demais objetos, como em grupo, ressignificar e compreender como, no sistema familiar ao qual integra, são apresentadas as falhas no uso das Ordens do Amor.

A introdução desta técnica no Direito brasileiro deu-se pela sua efetivação pelo magistrado Sami Storch na Vara de Família da Comarca de Castro Alves, interior da Bahia, no ano de 2006, como fase preparatória e antecessora às audiências de conciliação ou mediação. Mostrando-se a tentativa exitosa em virtude dos resultados obtidos - 91\% de conciliações em audiências em que uma das partes foi à técnica e $100 \%$ de conciliações quando ambas foram consteladas, nos anos de 2013 e 2014 - a iniciativa expandiu-se pelo território nacional, sendo utilizada constantemente em pelo menos 11 dos Estados federados, a exemplo de Alagoas, Pará, São Paulo, Rio Grande do Sul e Amapá.

Percebeu-se, diante das especificidades e complexidades das demandas referentes à violência doméstica que, entre os meios consensuais de resolução de conflitos - negociação, conciliação e mediação - seria esta última a mais adequada a intentar trabalhar com o problema-raiz da violência, vez que o que se buscaria 
seria a melhor significação do conflito pelas partes a fim de viabilizar o restabelecimento do diálogo entre elas, em especial quando ocorre a existência de filhos entre o ex ou atual casal, em um contexto de conflito de alta complexidade, poder de dano, consequências e sofrimento.

Em contrapartida, percebeu-se que, diante das demandas referentes à violência doméstica, a utilização dos ditos meios consensuais entre agressor e agredida mostra-se desarrazoada em dois pontos. Inicialmente, o uso de conciliações, na prática, impostas sem qualquer preparo técnico do magistrado ou conciliador para a devida e criteriosa utilização desta técnica, no âmbito dos Juizados Especiais, regidos pela Lei no 9.099/95, quando da inexistência da Lei Maria da Penha, relegava a gravidade dos crimes de violência pautados no gênero - e concebidos como violação aos direitos humanos desde a Convenção de Belém do Pará - a crimes de menor potencial ofensivo e, portanto, transacionáveis. Do mesmo modo, ainda nesse ponto, a inexistência de um diploma legal que protegesse a mulher diante da situação de vulnerabilidade expressada pela violência doméstica, a impelia a conciliar com o agressor, inclusive pela pressão social de continuidade da família e receio de perda de guarda dos filhos ou de lesão patrimonial.

Um segundo ponto a ser observado, já sob o manto da Lei Maria da Penha, é que a Secretaria Especial de Direitos Humanos dispõe que violações a direitos humanos não são mediáveis - constituindo a violência doméstica um deles.

Ocorre que, como demonstra a experiência da instituição do Núcleo Experimental de Mediação na Deam de Sergipe, o restabelecimento do diálogo entre as partes de um litígio de violência doméstica, especialmente quando há vínculos indissolúveis entre ambos, como a existência de filhos, permite que essa demanda e as demais, que transcorram nas Varas de Família, possam ser resolvidas de modo menos desgastante e mais eficaz para ambas as partes e para seus filhos.

Assim sendo, o que se buscaria com a mediação diante da violência doméstica e/ou intrafamiliar de gênero não seria a reconciliação do casal, mas sim a compreensão da gravidade, complexidade e naturalização das agressões sofridas pela mulher vítima e a oportunidade para que tanto a vítima quanto o agressor possam melhor compreender o fenômeno da violência doméstica no qual se encontram imersos, e assim, haver maior possibilidade de efetividade tanto das decisões e/ou sentenças proferidas no curso das ações judicializadas nestes tipos de demanda, quanto das decisões e sentenças prolatadas nas demanda de FAMílIA, envolvendo as mesmas partes, logo, os mesmos filhos, que frequentemente tramitam simultaneamente.

Devendo-se analisar a pertinência da mediação a cada caso concreto, acredita-se adicionalmente que o uso da técnica das Constelações Familiares nos casos de violência doméstica e de gênero pode se mostrar consentâneo não apenas com as previsões da Portaria no 125 de 2010 do CNJ - que prevê o estímulo do poder Judiciário a formas mais adequadas à resolução de conflitos levados ao Estado-juiz - como também, e primordialmente, a maior eficácia do enfrentamento do problema-raiz que levou as partes a buscarem as instituições do Sistema de Justiça.

É neste contexto de alta complexidade e gravidade que caracteriza a ocorrência da violência doméstica ou familiar de gênero que se deve considerar a possibilidade de uso da referida técnica também nesses casos, especialmente quando houver vínculos de parentalidade entre as partes, possibilitando inclusive que o agressor ressignifique, por meio da representação, os conceitos patriarcais por ele introjetados como fatores etiológicos e de risco pra a prática da violência contra a mulher em todas as suas modalidades.

\section{REFERÊNCIAS}

ALECRIM, Gisele Machado; SILVA, Eduardo Pordeus; ARAÚJO, Jailton Macena de. Autonomia da mulher sobre o seu corpo e a intervenção estatal. Revista Direito e Gênero, n. 2, p. 158-175, 2ㅇs semestre de 2014.

ALMEIDA, José Carlos Dias de. Constelação familiar sistêmica. 2008. Disponível em: <htp://henriquefernandes.com.br/ARTIGO\%2520CONSTELA\%25C3\%2587\%25C3\%2520CARLOS.pd>. Acesso em: 17 jul. 2017.

ALVES, Mariza Santos Pereira. A proteção constitucional do princípio da autonomia da vontade. 2007. Monografia (Programa de Pós-Graduação Lato Sensu em Direito Privado) - Instituto Brasiliense de Direito Público - IDP, Brasília, 2007.

BARSTED, Leila Linhares. Lei Maria da Penha: uma experiência bem-sucedida de advogacy feminista. In: CAMPOS, Carmen Hein de. Lei Maria da Penha comentada em uma perspectiva jurídico-feminista. Rio de Janeiro: Lumen Juris, 2011. p. 13-37.

BAVARESCO, Andréa Serra. Mediação: uma alternativa à jurisdição? 2006. 163 f. Dissertação (Mestrado em Direito) - Universidade Federal do Rio Grande do Sul, Porto Alegre, 2006. 
CALAZANS, Myllena; CORTES, láris. O processo de criação, aprovação e implementação da Lei Maria da Penha. In: CAMPOS, Carmen Hein de. Lei Maria da Penha comentada em uma perspectiva jurídico-feminista. Rio de Janeiro: Lumen Juris, 2011. p. 39-64.

CARVALHO, Elza Vicente. Constelações Familiares Sistêmicas. Revista Saúde Quântica, vol. 1, n. 1, p. 43-45, 2012.

CÉSPEDES, Adele Speck Rendón. A constelação familiar aplicada ao Direito Brasileiro a partir da Lei de Mediação. 2017. Monografa (Direito) - Universidade Federal de Santa Catarina, Florianópolis, 2017.

CHIQUETTI, Taciana; CRUZ, Carlos Henrique Souza. As constelações sistêmicas familiares na justiça do RN: uma interface entre a Psicologia e o Direito, 2016.

CONSELHO NACIONAL DE JUSTIÇA (CNJ). Audiência judicial ajuda mulheres a vencer o medo de agressores. 2017. Disponível em: <http://www.cnj.jus.br/noticias/cnj/85066-audiencia-judicial-ajuda-mulheres-a-vencer-o-medo-de-agressores>. Acesso em: 19 set. 2017.

. Constelação familiar ajuda a humanizar práticas de conciliação no judiciário. 2016. Disponível em: <http://www.cnj. jus.br/noticias/cnj/83766-constelacao-familiar-ajuda-humanizar-praticas-de-conciliacao-no-judiciario-2>. Acesso em: 19 jul. 2017.

. Juiz consegue 100\% de acordos usando técnica alemã antes das sessões de conciliação. 2014. Disponível em: <http:// www.cnj.jus.br/noticias/cnj/62242-juiz-consegue-100-de-acordos-usando-tecnica-alema-antes-das-sessoes-de-conciliacao>. Acesso em: 15 jul. 2017.

DIAS, Maria Berenice. A Lei Maria da Penha na Justiça: a efetividade da Lei 11.340/2006 de combate à violência doméstica e familiar contra a mulher. São Paulo: Ed. Revista dos Tribunais, 2007.

DINIZ, Débora. Bioética e gênero. Revista Bioética, vol. 16, n. 2, p. 207-216, 2008.

DINIZ, Débora; GUILLHEM, Dirce. Revista Bioética, vol. 7, n. 2, p. 1-5, 2000.

FONSECA, Cristiane Silva Marques da; SAUÁIA, Artenira da Silva e Silva. Defensor Público: agente mediador de conflitos em prol da pacificação social de adolescentes em conflito com a lei. In: CHAl, Cássius Guimarães (Org.); BAHIA, Alexandre Gustavo de Melo Franco et al. (Coord.). Mediação familiar, infância, idoso e gênero. Rio de Janeiro: Global Mediation, 2014. p. 150-163. GRINOVER, Ada Pellegrini. O minissistema brasileiro de Justiça consensual: compatibilidades e incompatibilidades, In: CARMONA, Carlos Alberto. Arbitragem e processo. 3. ed., rev. e ampl. São Paulo: Atlas, 2009. p. 1-30.

HELLINGER, Bert. Simetria oculta do amor. Trad. Newton A. Queiroz. 6. ed. São Paulo: Cultrix, 2015.

KATO, Shelma Lombardi de. Da equipe multidisciplinar - artigos 29 a 32. In: CAMPOS, Carmen Hein de. Lei Maria da Penha comentada em uma perspectiva jurídico-feminista. Rio de Janeiro: Lumen Juris, 2011. p. 347-355.

LAVIGNE, Rosane M. Reis; PERLINGEIRO, Cecília. Das medidas protetivas de urgência - artigos 18 a 21. In: CAMPOS, Carmen Hein de. Lei Maria da Penha comentada em uma perspectiva jurídico-feminista. Rio de Janeiro: Lumen Juris, 2011. p. $289-305$. MUSZKAT, Malvina Ester (Org.). Mediação de conflitos: pacificando e prevenindo a violência. São Paulo: Summus Editorial, 2003.

NOBRE, Maria Teresa; BARREIRA, César. Controle social e mediação de conflitos: as delegacias da mulher e a violência doméstica. Revista Sociologias, ano 10, n. 20, jul./dez., p. 138-163, 2008.

PASINATO, Wânia. Avanços e obstáculos na implementação da Lei 11.40/2006. 2011.

PIOVESAN, Flávia; PIMENTEL, Silvia. A Lei Maria da Penha na perspectiva da responsabilidade internacional do Brasil. In: CAMPOS, Carmen Hein de. Lei Maria da Penha comentada em uma perspectiva jurídico-feminista. Rio de Janeiro: Lumen Juris, 2011. p. 101-118.

SALES, Lília Maia de Morais. Mediare: um guia prático para mediadores. 2. ed. Fortaleza: Universidade de Fortaleza, 2004. VEZZULLA, Juan Carlos. Teoria e prática da mediação. 2. ed. Curitiba: CDD, 1998.

ZISMAN, Célia Rosenthal. O princípio da dignidade da pessoa humana. São Paulo: IOB Thomson, 2005. 